Letters to the Editor

NEUROSURGICAL FORUM

\section{Endoscopic endonasal transsphenoidal approach to pituitary adenomas}

TO THE EDITOR: We read with great interest the article by Juraschka et al. ${ }^{1}$ from the University of Toronto, Canada (Juraschka K, Khan OH, Godoy BL, et al: Endoscopic endonasal transsphenoidal approach to large and giant pituitary adenomas: institutional experience and predictors of extent of resection. J Neurosurg 121:75-83, July 2014). They timely and properly focus the readers' attention on the particular clinical and surgical challenges in the management of giant pituitary adenomas, which constitute a subgroup of lesions that have been classically defined by a maximum diameter $>4 \mathrm{~cm}$. They consider giant adenomas those tumors with a volume of at least $10 \mathrm{~cm}^{3}$ or a maximum diameter $\geq 3 \mathrm{~cm}$. As a matter of fact, in their study, in which they used the above-mentioned inclusion criteria, the authors analyzed the clinical and surgical outcomes in a series of 73 patients who underwent surgery via an endoscopic endonasal transsphenoidal approach at their institution in a 6.5-year timeframe. They report that they used, in almost one-third of their patients, an extended endoscopic approach.

Obviously, the majority of their patients harbored a clinically nonfunctioning pituitary macroadenoma and complained of visual disturbances (either visual acuity and/or visual field defects) and/or endocrine hypofunction. According to preoperative MRI, a cystic component was present in $30.1 \%$ of tumors, a hemorrhagic component in $24.7 \%$, sphenoid sinus invasion in $35.6 \%$, anterior extension in $16.4 \%$, posterior extension in $31.5 \%$, suprasellar lateral extension in $26.0 \%$, optic nerve compression in $94.5 \%$, and hydrocephalus in $5.5 \%$.

Such percentages, particularly the $35.6 \%$ with a component inside the sphenoid sinus or the $30.1 \%$ with the presence of a cystic or hemorrhagic lesion, in our opinion, are confusing since they do not actually indicate only those tumors that pose technical difficulties in their surgical management. In other words, what causes the difficulties in surgically treating giant adenomas are the supra-parasellar components of the tumor, which are those involving the most critical neurovascular structures, having a greater risk of injury by the surgeon. Indeed, a tumor with a diameter measuring more than 3 or $4 \mathrm{~cm}$, but with a reasonable part of it extending inside the sphenoid sinus or more downward, does not necessarily pose the same technical risks or have the same outcome as a surgically treated mass with a predominant component in the supra- parasellar areas, even if that mass has a smaller diameter. Similarly, an adenoma with a soft consistency or with a cystic component is easier to remove than a same-sized lesion with a harder texture; or a tumor predominantly in the midline has a location that is certainly more favorable for removal than a lesion with eccentric lateral paraventricular extensions. It is easily understood that the possibility of achieving gross-total removal is greater for adenomas, even giant ones, with more surgically favorable features (sizable component in the sphenoid sinus, soft consistency, no invasion of the cavernous sinuses, and so forth) than for a big adenoma with unfavorable features.

In the authors' study, however, considering such a heterogeneous group of lesions together, pooled only on the basis of measures and not stratifying them on the basis of their different characteristics, might in some way have corrupted the actual extent of resection rate, the overall visual outcome, and the percentage of complications, which deeply differ from one another if we consider the direction and site of growth of the neoplasm. Thus, we do not agree with the authors when they conclude that sphenoid sinus invasion may represent a tumor characteristic that decreases the likelihood of successful and complete endoscopic transsphenoidal surgery. The presence of a component in the sphenoid sinus, and therefore far from the neurovascular structures, might be considered a favorable feature in obtaining greater tumor debulking. On the contrary, in our experience, the true giant pituitary adenomas that extend mainly in the intracranial compartment present a greater rate of complications.

Finally, we are sincerely thankful to the authors for having focused attention on the surgical management of giant pituitary adenomas and the uncommon challenges they pose regarding the predictability of obtaining a grosstotal removal and improving preoperative deficits.

Paolo Cappabianca, MD
Luigi Maria Cavallo, MD, PhD
Domenico Solari, MD
Università degli Studi di Napoli Federico II, Naples, Italy
Felice Esposito, MD, PhD
Università degli Studi di Messina, Messina, Italy

DISCLOSURE

The authors report no conflict of interest.

\section{Reference}

1. Juraschka K, Khan OH, Godoy BL, Monsalves E, Kilian A, Krischek B, et al: Endoscopic endonasal transsphenoidal approach to large and giant pituitary adenomas: institutional 
experience and predictors of extent of resection. J Neurosurg 121:75-83, 2014

\section{Response}

No response was received from the authors of the original article.

\section{INCLUDE WHEN CITING}

Published online December 12, 2014; DOI: 10.3171/2014.8.JNS141716.

(c)AANS, 2015

\section{DTI in brain tumor surgery}

TO THE EDITOR: The article by Mandelli et al. ${ }^{4}$ and published recently in your journal has several interesting points (Mandelli ML, Berger MS, Bucci M, et al: Quantifying accuracy and precision of diffusion MR tractography of the corticospinal tract in brain tumors. J Neurosurg 121:349-358, August 2014).

The objective of this study was to test the accuracy of diffusion tensor imaging (DTI) and its reliability to guide real-time safe neurosurgical removal of a brain tumor. For this reason, I believe that this article presents an important contribution to the increasing literature related to functional neuroimaging technology and its role in improving neurosurgical operative technique.

However, Mandelli et al. ${ }^{4}$ reported a limitation associated with the use of DTI intraoperatively, manifested by poor sensitivity in detecting the lateral aspect of the corticospinal tract. This limitation recounted by the authors was attributed to problems in the technology itself; alternatively, we should consider that this limitation could be the result of tumor impact on the brain networks mediated by the neuroplasticity, ${ }^{1}$ or, in other words, because of a decline in the functionality of the corticospinal tract (which indeed might be transferred partially to another tract or network by the process of the neuroplasticity). This consideration is very important as it may affect the way that we interpret and utilize the data provided by DTI.

The above concept is supported by several clinical and research observations. For instance, Wang et al. showed that in brain tumor patients the brain networks are altered when compared with healthy controls. ${ }^{5}$ For example, theta band connectivity has been reported to be pathologically increased in brain tumor patients. The authors compared the functional brain networks of a group of patients with brain tumors before and after surgery. They found statistically significant changes in network features in the beta 13- to $30-\mathrm{Hz}$ band after the surgical intervention. ${ }^{5}$ These global alterations in functional brain networks could be explained theoretically by reviewing the findings of a recently published study conducted by Butz and van Ooyen on neuroplasticity. ${ }^{2}$ The authors pointed out that persistent local changes in the neuronal activities led to massive global structural and network changes according to a simple homeostatic regulation rule. ${ }^{2}$ To prove their concept, they showed how focal retinal lesions produce neuron and network changes in the visual cortex. ${ }^{2}$ Because brain tumors present a challenge to the local neural discharge homeostasis, and based on the previous concept, brain tumors should also lead to global changes in functional and even structural networks. This may explain several clinical observations in the context of brain tumors, such as recruitment of cortical areas ipsilateral to the tumor and redistribution of eloquent areas around the tumor and the fact that many patients with large intracranial tumors may present with minimal neurological deficits. ${ }^{1}$

The impact of brain tumors on brain functional networks (locally and globally) should receive more attention and promote fruitful research endeavors. Such research projects may pave the way for optimal ways of using DTI and other functional neuroimaging methods in neurosurgery and help anticipate potential surgical outcome.

Finally, and keeping in mind other concerns and limitations of DTI including its underestimation of long-range connections and its inability to capture the pathway (or more precisely, the directionality) of a fiber tract that is inconsistent with the normal anatomy, the recommendation of Mandelli et al. remains the best strategic plan in our contemporary neurosurgical practice, that is, to couple the use of DTI information with intraoperative electrophysiology mapping for neurosurgical resection of brain tumors.

\section{Asem Salma, MD King Faisal Specialist Hospital and Research Centre, Riyadh, Saudi Arabia}

\section{Acknowledgment}

I would like to thank Dr. Imad Kanaan for reviewing this letter and for his valuable advice.

\section{DISCLOSURE}

The author reports no conflict of interest.

\section{References}

1. Abd-El-Barr MM, Saleh E, Huang RY, Golby AJ: Effect of disease and recovery on functional anatomy in brain tumor patients: insights from functional MRI and diffusion tensor imaging. Imaging Med 5:333-346, 2013

2. Butz M, van Ooyen A: A simple rule for dendritic spine and axonal bouton formation can account for cortical reorganization after focal retinal lesions. PLoS Comput Biol 9:e1003259, 2013

3. Dietmar P: Viewpoint. The critical brain. Phys Rev Lett 6:47, 2013

4. Mandelli ML, Berger MS, Bucci M, Berman JI, Amirbekian B, Henry RG: Quantifying accuracy and precision of diffusion MR tractography of the corticospinal tract in brain tumors. J Neurosurg 121:349-358, 2014

5. Wang H, Douw L, Hernández JM, Reijneveld JC, Stam CJ, Van Mieghem P: Effect of tumor resection on the characteristics of functional brain networks. Phys Rev E Stat Nonlin Soft Matter Phys 82 (2 Pt 1):021924, 2010

\section{Response}

No response was received from the authors of the original article.

\section{INCLUDE WHEN CITING}

Published online December 19, 2014; DOI: 10.3171/2014.8.JNS141825.

CAANS, 2015 


\section{Simulation in neurosurgical education: where next?}

TO THE EDITOR: Kirkman et al. ${ }^{3}$ have completed a thorough and comprehensive review of the use of simulation in neurosurgical education and training and indeed of its use in assessment (Kirkman MA, Ahmed M, Albert AF, et al: The use of simulation in neurosurgical education and training. J Neurosurg 121:228-246, August 2014). As they have elegantly outlined, the literature is sparse and some of the studies are limited or flawed. As they have also stated, only two studies were randomized, but this is not necessarily a barrier to quality in medical education research. Indeed Norman has written of the perils of this form of research in medical education using the acronym RCT to mean "results confounded and trivial." On another note, none of the simulation studies used high-fidelity environments, but once again this may not be a marker of poor quality. How high fidelity does a simulator have to be in the first place? According to Ker et al., there are some aspects of flying commercial jets that "are best taught using computer based simulations rather than full immersion simulators." 2

Towards the end of the paper the authors point out potential future directions of research. Their suggestions are helpful, yet there are other possible directions of travel. As in other specialties, many of the skills of the neurosurgeon will be generic and applicable to a range of surgical specialties, but some skills will be unique or will need to be developed to a higher level in the budding neurosurgery trainee than in other trainees. One particular required combination of attributes might be patience and staminaneurosurgery lasts many hours and requires prolonged and intense concentration. Could simulators be developed and evaluated that enable trainees to develop these attributes? Not all medical and surgical simulators need high levels of technology to provide a good learning experience; however, it is probable that most neurosurgical simulators do require high levels of technology and need to train and test learners' skills in interacting with this technology. All surgeons need good judgment, but in neurosurgery the need for judgment is enhanced. One of the main judgments is whether or not to operate-perhaps such decision points could be built into simulator scenarios and simulator programs. Lastly, there is a growing movement in medical and surgical education towards mastery learning. ${ }^{1}$ In neurosurgery, competence is probably not enough. Trainers and trainees should aim for excellence and should use mastery-learning techniques built into simulator programs to achieve this.

\section{Kieran Walsh \\ BMJ Learning, London, United Kingdom}

DISCLOSURE

The author reports no conflict of interest.

\section{References}

1. Barsuk JH, Cohen ER, Caprio T, McGaghie WC, Simuni T, Wayne DB: Simulation-based education with mastery learn- ing improves residents' lumbar puncture skills. Neurology 79:132-137, 2012

2. Ker J, Hogg G, Maran N: Cost effective simulation, in Walsh $\mathrm{K}$ (ed): Cost Effectiveness in Medical Education. Oxford: Radcliffe, 2010, pp 61-71

3. Kirkman MA, Ahmed M, Albert AF, Wilson MH, Nandi D, Sevdalis N: The use of simulation in neurosurgical education and training. J Neurosurg 121:228-246, 2014

4. Norman G: RCT = results confounded and trivial: the perils of grand educational experiments. Med Educ 37:582-584, 2003

\section{Response}

No response was received from the authors of the original article.

INCLUDE WHEN CITING

Published online December 12, 2014; DOI: 10.3171/2014.7.JNS141540.

cAANS, 2015

\section{SEEG has the lowest rate of complications}

TO THE EDITOR: We read with great interest the paper by Tebo et al. ${ }^{18}$ (Tebo CC, Evins AI, Christos PJ, et al: Evolution of cranial epilepsy surgery complication rates: a 32-year systematic review and meta-analysis. J Neurosurg 120:1415-1427, June 2014). In their paper the authors state, "Complication rates for focal resective epilepsy surgery have decreased dramatically over time. In particular, the risk of permanent neurological deficits is extremely low." The authors reported on the results of a large systematic review covering 32 years of literature, between 1980 and 2012. Moreover, the literature review was quantitatively complemented by an excellent meta-analysis performed on the 3 groups of considered patients: Group A, who received temporal resections; Group B, who underwent extra-temporal resections; and Group $\mathrm{C}$, who were evaluated by invasive electroencephalography (EEG) recording by means of subdural grids or depth electrodes. The authors' declared goal was to highlight the low morbidity rate of such diagnostic and therapeutic procedures, and they concluded with a plea in favor of epilepsy surgery. In fact, the authors wrote ".... a temporal lobectomy, with or without an amygdalohippocampectomy, has a $0.8 \%$ risk of permanent deficits. This risk has dropped by $92 \%$ over time." Moreover, they also reported, "Permanent neurological deficits after extratemporal epilepsy surgery have decreased in recent years by $64 \%$, from $9.0 \%$ to $3.2 \%$...." Conversely, as far as invasive EEG recordings are concerned, the authors reported that, although "neurological complications decreased from $6.3 \%$ in $1980-1995$ to $3.0 \%$ in $1996-2012 \ldots$ wound infections/meningitis increased from $2.3 \%$ to $4.3 \%$, as did hemorrhage/hematoma rising from $1.9 \%$ to $4.2 \%$." The latter point deserves further discussion and comments. In fact, the reader receives the take-home message that the use of invasive EEG recording increases the cumulative risk of the overall procedure by a nonnegligible factor, and that the safety of such procedures has decreased with time. 
In our opinion, this conclusion arises from the fact that, surprisingly, a number of papers were not included in the group of the selected studies, despite the fact that they met the eligibility criteria. Of note, we reran on PubMed the same search query reported by the authors, and all studies listed in Table 1 were included in our query results.

Stereoelectroencephalography (SEEG) is a methodology developed at Hôpital Saint Anne, Paris, France, by Bancaud and Talairach. ${ }^{3}$ These authors were the first to record the ictal electrical activity from the cerebral cortex using stereotactically implanted electrodes in the late $1950 \mathrm{~s},{ }^{2}$ and they subsequently coined the term "stereoelectroencephalography" in 1962. 'Different from depth electrodes, commonly used for lateralizing seizure onset, SEEG is steered to define the epileptogenic zone using a larger number of stereotaxic trajectories planned to verify a working hypothesis and therefore arranged according to the specific anatomo-electro-clinical requirements of each patient. ${ }^{15}$ Some studies clearly stated that, despite the number of electrodes, this result is obtained with a very low complication rate; McGonigal et al. ${ }^{14}$ and GonzalezMartinez et al. ${ }^{12}$ reported hemorrhagic complications in $3 \%$ and $2.5 \%$ of cases, respectively. Recently, our group reported the results from a consecutive series of 500 SEEG procedures, with the last 81 procedures (1050 electrodes) performed according to an updated workflow. ${ }^{6}$ Only 4 minor complications and 1 case of status epilepticus occurred with the new method. Moreover, after the period analyzed in the study, we performed 84 additional SEEG implantations (1091 electrodes) with no additional complications (unpublished data). Thus, considering our last 165 SEEG procedures performed with the updated workflow, the rate of major and minor complications was $0.6 \%$ and $2.4 \%$, respectively.

Tebo et al..$^{18}$ hope for the future the development of smaller and thinner grids for subdural recording, expecting that this will lead to a morbidity reduction. On the contrary, we foresee that the progressive rediscovering of SEEG methodology outside the European borders will be the most important advancement in the field, potentially resulting in both a significant reduction in the complication rate and a better definition of the epileptogenic zone, due to the possibility of direct recording of electrical brain activity, not only from the surface of the hemispheres, but also from the depth of the sulci and from any subcortical structure or lesion. Through a large number of multilead intracerebral electrodes implanted according to a working hypothesis on the epileptogenic network, SEEG is the only methodology that provides essential 3D information about the spatial and temporal organization of the ictal discharge. Although SEEG is gaining popularity, the systematic review of Tebo et al. ${ }^{18}$ ignored all related papers, as well as the similar study published by Hader et al. in 2013. ${ }^{13}$ The striking underestimation of SEEG studies from such otherwise meticulous systematic reviews, despite the fact that they meet all the eligibility criteria, is difficult to understand.

In conclusion, we would like to emphasize the historical rule and the progressive spreading of SEEG methodology, hoping that this will support a more confident attitude toward surgery to treat drug-resistant epilepsies, without undue fear of invasive recordings.

TABLE 1. Some studies fulfilling the eligibility criteria but not included in the authors' results*

\begin{tabular}{|c|c|c|c|c|}
\hline Authors \& Year & No. of Procedures & No. of Electrodes \& Type & $\begin{array}{l}\text { Direct Morbidity } \\
\text { (major, minor)† }\end{array}$ & No. of Deaths \\
\hline \multicolumn{5}{|l|}{ SEEG } \\
\hline Munari et al, 1994 & 70 & 714 SEEG electrodes & $1.4 \%, 1.4 \%$ & \\
\hline Cossu et al., 2005 & 215 & 2666 SEEG electrodes & $2.8 \%, 2.8 \%$ & \\
\hline Cossu et al., 2012 & 16 & 192 SEEG electrodes & & 1 \\
\hline Gonzalez-Martinez et al., $2013 \S$ & 100 & 1310 SEEG electrodes & $0 \%, 3 \%$ & \\
\hline Cardinale et al., 2013‡ף & 500 & 6496 electrodes & $2.2 \%, 2.4 \%$ & 1 \\
\hline \multicolumn{5}{|l|}{ Other invasive techniques } \\
\hline Adelson et al., 1995 & 31 & Grids, strips & $3.2 \%, 0.7 \%$ & \\
\hline Behrens et al., 1997 & 279 & Grids, strips, DEs & $2.9 \%, 0 \%$ & \\
\hline Wiggins et al., 1999 & 38 & Grids, strips, DEs & $10.5 \%, 0 \%$ & \\
\hline Musleh et al., 2006 & 34 & Grids, strips, DEs & $5.9 \%, 0 \%$ & \\
\hline De Almeida et al., 2006 & 224 & SEEG, DEs, CEs & $4.5 \%, 13.8 \%$ & \\
\hline Burneo et al., 2006 & 116 & Grids, strips, DEs & $3.4 \%, 1.7 \%$ & \\
\hline Tanriverdi et al., 2009 & 491 & SEEG, DEs, CEs & $1.4 \%, 3.7 \%$ & \\
\hline \multicolumn{5}{|c|}{$\begin{array}{l}\text { CE = cortical electrode; DE = depth electrode. } \\
\text { * All listed studies meet the authors' inclusion criteria of "full-length original peer-reviewed articles published in English between } 1980 \text { and } \\
2012 \text { that contained at least } 2 \text { patients of any age undergoing resective epilepsy surgery and/or invasive electrode placement." } \\
\dagger \text { We coded complications as major when they required surgical treatment, when resulting in a permanent neurological deficit, or for their } \\
\text { potential severity. } \\
\text { † These studies are from the same group, with an overlapping of the analyzed populations. The deceased patient is the same: a } 3 \text {-year-old } \\
\text { child died due to postimplantation severe hyponatremia. This could be therefore considered as indirect mortality. } \\
\S \text { Published online September } 27,2012 \text {. } \\
\text { † Published online November } 19,2012 \text {. }\end{array}$} \\
\hline
\end{tabular}


Francesco Cardinale, MD Massimo Cossu, MD

"Claudio Munari" Center for Epilepsy and Parkinson Surgery,

Niguarda Hospital, Milan, Italy

\section{DISCLOSURE}

Dr. Cardinale reports receiving consulting fees from Renishaw-mayfield. Dr.

Cossu reports no conflict of interest.

\section{References}

1. Adelson DP, Black PM, Madsen JR, Kramer U, Rockoff MA, Riviello JJ, et al: Use of subdural grids and strip electrodes to identify a seizure focus in children. Pediatr Neurosurg 22:174-180, 1995

2. Bancaud J: [Contribution of functional exploration by stereotaxic ways to the surgery of epilepsy; 8 case reports.] Neurochirurgie 5:55-112, 1959 (Fr)

3. Bancaud J, Talairach J: La StéréoÉlectroEncéphaloGraphie dans l'épilepsie. Paris: Masson, 1965, pp 3-5

4. Behrens E, Schramm J, Zentner J, König R: Surgical and neurological complications in a series of 708 epilepsy surgery procedures. Neurosurgery 41:1-10, 1997

5. Burneo JG, Steven DA, McLachlan RS, Parrent AG: Morbidity associated with the use of intracranial electrodes for epilepsy surgery. Can J Neurol Sci 33:223-227, 2006

6. Cardinale F, Cossu M, Castana L, Casaceli G, Schiariti MP, Miserocchi A, et al: Stereoelectroencephalography: surgical methodology, safety, and stereotactic application accuracy in 500 procedures. Neurosurgery 72:353-366, 2013

7. Chauvel P: Contributions of Jean Talairach and Jean Bancaud to epilepsy surgery, in Lüders HO, Comair YG (eds): Epilepsy Surgery, ed 2. Philadelphia: Lippincott Williams \& Wilkins, 2001, pp 35-41

8. Cossu M, Cardinale F, Castana L, Citterio A, Francione S, Tassi L, et al: Stereoelectroencephalography in the presurgical evaluation of focal epilepsy: a retrospective analysis of 215 procedures. Neurosurgery 57:706-718, 2005

9. Cossu M, Schiariti M, Francione S, Fuschillo D, Gozzo F, Nobili L, et al: Stereoelectroencephalography in the presurgical evaluation of focal epilepsy in infancy and early childhood. J Neurosurg Pediatr 9:290-300, 2012

10. De Almeida AN, Olivier A, Quesney F, Dubeau F, Savard G, Andermann F: Efficacy of and morbidity associated with stereoelectroencephalography using computerized tomography- or magnetic resonance imaging-guided electrode implantation. J Neurosurg 104:483-487, 2006

11. Gonzalez-Martinez J, Bulacio J, Alexopoulos A, Jeha L, Bingaman W, Najm I: Stereoelectroencephalography in the "difficult to localize" refractory focal epilepsy: early experience from a North American epilepsy center. Epilepsia 54:323-330, 2013

12. Gonzalez-Martinez J, Mullin J, Vadera S, Bulacio JC, Hughes GL, Jones S, et al: Stereotactic placement of depth electrodes in medically intractable epilepsy. J Neurosurg 120:639-644, 2014

13. Hader WJ, Tellez-Zenteno J, Metcalfe A, Hernandez-Ronquillo L, Wiebe S, Kwon CS, et al: Complications of epilepsy surgery: a systematic review of focal surgical resections and invasive EEG monitoring. Epilepsia 54:840-847, 2013

14. McGonigal A, Bartolomei F, Régis J, Guye M, Gavaret M, Trébuchon-Da Fonseca A, et al: Stereoelectroencephalography in presurgical assessment of MRI-negative epilepsy. Brain 130:3169-3183, 2007

15. Munari C, Hoffmann D, Francione S, Kahane P, Tassi L, Lo Russo G, et al: Stereo-electroencephalography methodology: advantages and limits. Acta Neurol Scand Suppl 152:5669, 1994

16. Musleh W, Yassari R, Hecox KE, Kohrman M, Chico M,
Frim D: Low incidence of subdural grid-related complications in prolonged pediatric EEG monitoring. Pediatr Neurosurg 42:284-287, 2006

17. Tanriverdi T, Ajlan A, Poulin N, Olivier A: Morbidity in epilepsy surgery: an experience based on 2449 epilepsy surgery procedures from a single institution. J Neurosurg 110:1111-1123, 2009

18. Tebo CC, Evins AI, Christos PJ, Kwon J, Schwartz TH: Evolution of cranial epilepsy surgery complication rates: a 32-year systematic review and meta-analysis. J Neurosurg 120:1415-1427, 2014

19. Wiggins GC, Elisevich K, Smith BJ: Morbidity and infection in combined subdural grid and strip electrode investigation for intractable epilepsy. Epilepsy Res 37:73-80, 1999

\section{Response}

We thank Dr. Cardinale and Dr. Cossu for their insightful comments. In regard to SEEG, we concur that this technique will continue to play an important role in the clinical determination of the epileptogenic zone and believe that complication rates of SEEG should continue to be closely studied. Regarding the lack of included papers involving SEEG in our meta-analysis, SEEG was not an exclusion criterion but it also was not included in our search criteria. As stated in the Data Collection subsection of our Methods, only studies with overlapping patient data, case reports, and technical notes were excluded as well as studies that did not report complications-related data, reported only an aggregate complication rate, or discussed complications in a purely qualitative manner.

Concerning the listed papers that Drs. Cardinale and Cossu state fulfilled "the eligibility criteria but [were] not included," the Munari et al. ${ }^{9}$ study was not recognized as being eligible among the citations our search yielded; the Behrens et al. ${ }^{2}$ study was excluded due to our inability to attribute complication rates to specific procedure types (or one of our identified groups); and the Tanriverdi et al. ${ }^{12}$ study was excluded due to an overlapping patient population with a second study. ${ }^{11}$ The study by Gonzalez-Martinez et al. ${ }^{8}$ was published after our search period concluded, and that by Cardinale et al. ${ }^{4}$ was published at the very end of our search period and was not identified during our literature search. Upon replication of our search strategy, the studies by Wiggins et al., ${ }^{13}$ Musleh et al.. ${ }^{10}$ and De Almeida et al. ${ }^{7}$ were not identified in the yielded citations. The remaining papers, those by Cossu et al., ${ }^{5,6}$ Adelson et al., ${ }^{1}$ and Burneo et al., ${ }^{3}$ were either not identified by our search strategy in 2013 or were not recognized as eligible studies.

We maintain that grid implantation carries a higher risk of infection/meningitis or hemorrhage/hematoma than resection and should be considered only in patients in whom the results will significantly impact eventual resection. However, we acknowledge that these findings may not be representative of SEEG, as we were unable to analyze sufficient data on this technique and defer to the esteemed work of Cardinale et al. and Cossu et al., ${ }^{4-6}$ - among other studies $^{8,9}$-for SEEG-specific complication rates.

Alexander I. Evins, BS Collin C. Tebo, BS Theodore H. Schwartz, MD Weill Cornell Medical College, New York, NY 


\section{References}

1. Adelson DP, Black PM, Madsen JR, Kramer U, Rockoff MA, Riviello JJ, et al: Use of subdural grids and strip electrodes to identify a seizure focus in children. Pediatr Neurosurg 22:174-180, 1995

2. Behrens E, Schramm J, Zentner J, König R: Surgical and neurological complications in a series of 708 epilepsy surgery procedures. Neurosurgery 41:1-10, 1997

3. Burneo JG, Steven DA, McLachlan RS, Parrent AG: Morbidity associated with the use of intracranial electrodes for epilepsy surgery. Can J Neurol Sci 33:223-227, 2006

4. Cardinale F, Cossu M, Castana L, Casaceli G, Schiariti MP, Miserocchi A, et al: Stereoelectroencephalography: surgical methodology, safety, and stereotactic application accuracy in 500 procedures. Neurosurgery 72:353-366, 2013

5. Cossu M, Cardinale F, Castana L, Citterio A, Francione S, Tassi L, et al: Stereoelectroencephalography in the presurgical evaluation of focal epilepsy: a retrospective analysis of 215 procedures. Neurosurgery 57:706-718, 2005

6. Cossu M, Schiariti MP, Francione S, Fuschillo D, Gozzo F, Nobili L, et al: Stereoelectroencephalography in the presurgical evaluation of focal epilepsy in infancy and early childhood. J Neurosurg Pediatr 9:290-300, 2012

7. De Almeida AN, Olivier A, Quesney F, Dubeau F, Savard G, Andermann F: Efficacy of and morbidity associated with stereoelectroencephalography using computerized tomography- or magnetic resonance imaging-guided electrode implantation. J Neurosurg 104:483-487, 2006

8. Gonzalez-Martinez J, Mullin J, Vadera S, Bulacio JC, Hughes GL, Jones S, et al: Stereotactic placement of depth electrodes in medically intractable epilepsy. J Neurosurg 120:639-644, 2014

9. Munari C, Hoffmann D, Francione S, Kahane P, Tassi L, Lo Russo G, et al: Stereo-electroencephalography methodology: advantages and limits. Acta Neurol Scand Suppl 152:5669, 1994

10. Musleh W, Yassari R, Hecox KE, Kohrman M, Chico M, Frim D: Low incidence of subdural grid-related complications in prolonged pediatric EEG monitoring. Pediatr Neurosurg 42:284-287, 2006

11. Ozlen F, Asan Z, Tanriverdi T, Kafadar A, Ozkara C, Ozyurt E, et al: Surgical morbidity of invasive monitoring in epilepsy surgery: an experience from a single institution. Turk Neurosurg 20:364-372, 2010

12. Tanriverdi T, Ajlan A, Poulin N, Olivier A: Morbidity in epilepsy surgery: an experience based on 2449 epilepsy surgery procedures from a single institution. J Neurosurg 110:1111-1123, 2009

13. Wiggins GC, Elisevich K, Smith BJ: Morbidity and infection in combined subdural grid and strip electrode investigation for intractable epilepsy. Epilepsy Res 37:73-80, 1999

\section{INCLUDE WHEN CITING}

Published online December 19, 2014; DOI: 10.3171/2014.7.JNS141680.

(c)AANS, 2015

\section{Endoscopic endonasal posterior clinoidectomy}

TO THE EDITOR: We read with interest the article by Fernandez-Miranda et al. ${ }^{1}$ regarding a new technique for performing endoscopic endonasal posterior clinoidectomy (Fernandez-Miranda JC, Gardner PA, Rastelli MM Jr, et al: Endoscopic endonasal transcavernous posterior clinoidectomy with interdural pituitary transposition. Technical note. J Neurosurg 121:91-99, July 2014).
The authors described an innovative surgical technique performed through the cavernous sinus, with an interdural dissection taking advantage of the natural corridor provided by the separation of the inner and outer dural layers at the lateral margin of the sellae. This corridor provides access to the posterior clinoid process, making the endoscopic endonasal posterior clinoidectomy a safe and effective procedure. The approach was performed in 12 patients (6 with chordomas, 5 with petroclival meningiomas, and 1 with an epidermoid tumor), with great clinical results and no permanent hypopituitarism, diabetes insipidus, or neurovascular injuries. The impeccable quality of the anatomical dissections together with the detailed description of the surgical approach helps the reader to understand the complex anatomy of this region seen from the endoscopic endonasal view. The authors are to be congratulated on the excellent quality of the study and the clinical results.

In contrast to the Pittsburgh group's experience, we have described a purely extradural posterior clinoidectomy. ${ }^{2} \mathrm{We}$ have performed this approach safely in dozens of patients and have formed the opinion that in the majority of cases a purely extradural approach is sufficient to achieve an adequate posterior clinoidectomy. In those cases in which the extradural approach is not sufficient we have used the interdural approach, as described expertly in this article. Hence, we use the interdural approach more selectively, as needed, and it is possible to convert easily from the extradural to the interdural approach. Overall, it is our opinion that an extradural approach is safer because the dura mater can serve as a natural protector against neurovascular injury. There is also the option of working both above and below the pituitary gland to reach the interpeduncular fossa and retroinfundibular area, thereby avoiding damage to the pituitary gland and its blood supply. ${ }^{3}$ Making an analogy to the transcranial anterior clinoidectomy, which can be performed intra- or extradurally, there are probably indications for both inter- and extradural posterior clinoidectomy. Ultimately, the idea is to avoid a complete pituitary transposition, which often causes hypopituitarism.

Modern skull base neurosurgery is based on tailoring the approach for each patient. Thus, the new technique described by the authors is an important addition to skull base surgery, but in our opinion should be reserved for those posterior clinoids that cannot be removed extradurally, rather than being the default operation in all cases.

Danilo Silva, MD Cleveland Clinic, Neurological Institute, Cleveland, $\mathrm{OH}$

Moshe Attia, MD

Rambam Health Care Campus, Haifa, Israel

Theodore H. Schwartz, MD

Weill Cornell Medical College, NewYork-Presbyterian Hospital,

New York, NY

\section{DISCLOSURE}

Dr. Schwartz is a consultant for Karl Storz, and he owns stock in Vision Sense. $\mathrm{He}$ also receives support from the NIH for research not related to this study.

\section{References}

1. Fernandez-Miranda JC, Gardner PA, Rastelli MM Jr, PerisCelda M, Koutourousiou M, Peace D, et al: Endoscopic endonasal transcavernous posterior clinoidectomy with in- 
terdural pituitary transposition. Technical note. J Neurosurg 121:91-99, 2014

2. Silva D, Attia M, Kandasamy J, Alimi M, Anand VK, Schwartz TH: Endoscopic endonasal posterior clinoidectomy. Surg Neurol Int 3:64, 2012

3. Silva D, Attia M, Kandasamy J, Alimi M, Anand VK, Schwartz TH: Endoscopic endonasal transsphenoidal "above and below" approach to the retroinfundibular area and interpeduncular cistern-cadaveric study and case illustrations. World Neurosurg 81:374-384, 2014

\section{Response}

Thank you for the opportunity to reply to the Letter to the Editor you received with regard to our article. We would also like to thank Drs. Silva, Attia, and Schwartz from Cornell University for their kind comments. However, we disagree with certain aspects of their letter.

First, and perhaps most important, it is key not to lose historical perspective when describing "new" or "modified" techniques. The surgical technique and application for an endoscopic endonasal, purely extradural posterior clinoidectomy was originally described in a seminal publication by the Pittsburgh group led by Amin Kassam in 2005. This publication literally states: "Subsellar extradural removal of the posterior clinoid and dorsum sellae ... the posterior clinoid and dorsum sellae can also be removed via a completely extrasellar approach.... The pituitary, with dura mater intact, is elevated superiorly.... The dura over the sella is not opened.... With the pituitary gland elevated, the dorsum sellae and posterior clinoid can be drilled using a 1-mm diamond bit or a rongeur...." In 2012, the Cornell group provided a more complete description of the surgical anatomy for the extradural posterior clinoidectomy technique by performing dissections in 5 anatomical specimens. ${ }^{3}$

Continued clinical experience by the Pittsburgh group resulted in further refinement of the technique to provide a balance of optimal exposure with preservation of pituitary function, as documented in subsequent publications: the intradural pituitary transposition and posterior clinoidectomy by Kassam et al. in $2008,{ }^{2}$ and then the interdural transcavernous posterior clinoidectomy described in the article under discussion. We have found that the purely extradural posterior clinoidectomy, although still very useful in selected cases, does not provide direct visualization and access to the top and posterolateral tip of the posterior clinoid and its ligamentous attachments. It is a blind maneuver that in case of prominent clinoids or calcified dural attachments is neither safe nor effective. In our experience in cases in which we had performed an extradural posterior clinoidectomy and thought we had removed the clinoid completely, there was often still a portion of the clinoid remaining.

In regard to the statement "an extradural approach is safer because the dura mater can serve as a natural protector against neurovascular injury," we would like to point out that the posterior clinoid is an interdural (intracavernous) structure and as such, the outer dural layer of the cavernous sinus is always going to be opened, as evidenced by the typical venous bleeding that occurs after posterior clinoidectomy. The difference between the extradural and the interdural approach resides precisely on whether the outer dural layer is disrupted in a noncontrolled fashion while removing the posterior clinoid extradurally, or whether the outer dural layer is widely open in a controlled fashion, providing direct visualization of the internal carotid artery (ICA) and the inferior hypophyseal artery (IHA) when performing an interdural transcavernous approach. The outer layer of dura, rather than providing protection to the ICA and IHA, prevents their visualization when removing the clinoid. It is in fact the removal of the posterior clinoid from within the cavernous sinus that risks vascular injury, and we believe this is better prevented with direct visualization. We would also like to emphasize the importance of avoiding avulsion of the IHA from the ICA wall when removing the posterior clinoid, which we believe is better prevented with the interdural rather than the extradural approach.

Certainly there is always variability of the surgical anatomy depending on the patient and the pathology. Whereas it is clear that in some cases, such as clival chordomas without significant involvement of dorsum sella and posterior clinoids, a partial posterior clinoidectomy is sufficient, in many others, such as extensive chordomas or petroclival meningiomas, a complete posterior clinoidectomy is mandatory. The ease with which this can be performed and the technique used should be tailored to the individual patient and pathology. Like many newer techniques, this facet of endonasal surgery is likely to be better elucidated through further peer-reviewed clinical series. Our colleagues at Cornell have always been an important group in this process and we look forward to their future contributions.

Juan C. Fernandez-Miranda, MD

Paul A. Gardner, MD

Carl H. Snyderman, MD, MBA

University of Pittsburgh School of Medicine, Pittsburgh, PA

\section{References}

1. Kassam A, Snyderman CH, Mintz A, Gardner P, Carrau RL: Expanded endonasal approach: the rostrocaudal axis. Part II. Posterior clinoids to the foramen magnum. Neurosurg Focus 19(1):E4, 2005

2. Kassam AB, Prevedello DM, Thomas A, Gardner P, Mintz A, Snyderman C, et al: Endoscopic endonasal pituitary transposition for a transdorsum sellae approach to the interpeduncular cistern. Neurosurgery (3 Suppl 1) 62:S57-S74, 2008

3. Silva D, Attia M, Kandasamy J, Alimi M, Anand VK, Schwartz TH: Endoscopic endonasal posterior clinoidectomy. Surg Neurol Int 3:64, 2012

\section{INCLUDE WHEN CITING}

Published online December 19, 2014; DOI: 10.3171/2014.8.JNS141783.

(c)AANS, 2015

\section{Regarding Bering's hypothesis on choroid plexus pulsatility}

TO THE EDITOR: I read with great interest the article by Matsumae et al. ${ }^{12}$ (Matsumae M, Hirayama A, Atsumi 
$\mathrm{H}$, et al: Velocity and pressure gradients of cerebrospinal fluid assessed with magnetic resonance imaging. J Neurosurg 120:218-227, January 2014).

In this article, the authors clearly describe the CSF movements at the intracranial level based on speed and pressure gradients. I was gladly surprised by the images regarding the nonsignificant pressure gradient around the choroid plexus. Thus, the choroid plexus of the body of the ventricle seems to scarcely contribute to the oscillating CSF. In 1955 Bering $^{1}$ proposed that the choroid plexuses were the structures responsible for the pulsatility of the CSF, considering that they would have the capacity for ingurgitating and voiding with each cardiac cycle. Even though some papers questioned these conclusions, ${ }^{4,7,10,13}$ the hypothetical pulsatility of the choroid plexus has been taken as valid in various studies. ${ }^{2,3,5,6,8,9,11,14-17}$ However, none of the reports, regardless of what position they had taken, including the present article and Bering's, studied the pulsatility of the choroid plexus in a direct way.

In my own endoscopic and ultrasonographic (B-mode) experience, the choroid plexus of the lateral ventricles has never shown volumetric changes despite the presence of pulsatile brain movements (unpublished data). Indeed, choroid plexus did show movements "in block," such as being "dragged" by the surrounding CSF, or "impulsed" by their insertion points, or a "vibrating" or "creeping" motion because of the movements of their principal vessels. I consider the choroid plexus volumetric changes to be macroscopically negligible.

Matsumae et al. ${ }^{12}$ point out that their results are not "entirely consistent" with the hypothesis of pulsatile choroid plexus. Perhaps Bering's assertion of the choroid plexus as a CSF pump should, in the future, not be considered as a real pathophysiological mechanism.

I congratulate the authors for such an elegant work.

Nelson Picard, MD, PhD Abraham Piñeyro Hospital, Buenos Aires, Argentina

\section{DISCLOSURE}

The author reports no conflict of interest.

\section{References}

1. Bering EA Jr: Choroid plexus and arterial pulsation of cerebrospinal fluid. Demonstration of the choroid plexus as a cerebrospinal fluid pump. AMA Arch Neurol Psychiatry 73:165-172, 1955

2. Bradley WG Jr, Kortman KE, Burgoyne B: Flowing cerebrospinal fluid in normal and hydrocephalic states: appearance on MR images. Radiology 159:611-616, 1986

3. Cardoso ER, Rowan JO, Galbraith S: Analysis of the cerebrospinal fluid pulse wave in intracranial pressure. J Neurosurg 59:817-821, 1983

4. Du Boulay GH, O'Connell J, Currie J, Bostick T, Verity P: Further investigations on pulsatile movements in the cerebrospinal fluid pathways. Acta Radiol Diagn (Stockh) 13:496-523, 1972

5. Egnor M, Wagshul M, Zheng L, Rosiello A: Resonance and the synchrony of arterial and CSF pulsations. Pediatr Neurosurg 38:273-276, 2003 (Letter)

6. Egnor M, Zheng L, Rosiello A, Gutman F, Davis R: A model of pulsations in communicating hydrocephalus. Pediatr Neurosurg 36:281-303, 2002

7. Feinberg DA, Mark AS: Human brain motion and cerebrospi- nal fluid circulation demonstrated with MR velocity imaging. Radiology 163:793-799, 1987

8. Gardner WJ: Hydrodynamic mechanism of syringomyelia: its relationship to myelocele. J Neurol Neurosurg Psychiatry 28:247-259, 1965

9. Henry-Feugeas MC, Idy-Peretti I, Blanchet B, Hassine D, Zannoli G, Schouman-Claeys E: Temporal and spatial assessment of normal cerebrospinal fluid dynamics with MR imaging. Magn Reson Imag 11:1107-1118, 1993

10. Laitinen L: Origin of arterial pulsation of cerebrospinal fluid. Acta Neurol Scand 44:168-176, 1968

11. Linninger AA, Tsakiris C, Zhu DC, Xenos M, Roycewicz $\mathrm{P}$, Danziger Z, et al: Pulsatile cerebrospinal fluid dynamics in the human brain. IEEE Trans Biomed Eng 52:557-565, 2005

12. Matsumae M, Hirayama A, Atsumi H, Yatsushiro S, Kuroda $\mathrm{K}$ : Velocity and pressure gradients of cerebrospinal fluid assessed with magnetic resonance imaging. J Neurosurg 120:218-227, 2014

13. Milhorat TH: The third circulation revisited. J Neurosurg 42:628-645, 1975

14. Pettorossi VE, Di Rocco C, Mancinelli R, Caldarelli M, Velardi F: Communicating hydrocephalus induced by mechanically increased amplitude of the intraventricular cerebrospinal fluid pulse pressure: rationale and method. Exp Neurol 59:30-39, 1978

15. Rengachary SS, Watanabe I, Brackett CE: Pathogenesis of intracranial arachnoid cysts. Surg Neurol 9:139-144, 1978

16. Wilson $\mathrm{CB}$, Bertan V: Interruption of the anterior choroidal artery in experimental hydrocephalus. Arch Neurol 17:614-619, 1967

17. Zhu DC, Xenos M, Linninger AA, Penn RD: Dynamics of lateral ventricle and cerebrospinal fluid in normal and hydrocephalic brains. J Magn Reson Imaging 24:756-770, 2006

\section{Response}

We are deeply grateful to Dr. Nelson Picard for showing such interest in and taking the time to comment on our article.

The video images in our article demonstrate that there is no significant pressure gradient around the choroid plexus of the lateral ventricles. Bering's classic research in a canine model indicated that unilateral choroid plexectomy of the lateral ventricle and concurrent occlusion of the foramen of Monro due to plugging resulted in a marked decrease in intraventricular CSF pulsation synchronous with the cardiac pulse, compared to the pulsation strength in the untreated contralateral lateral ventricle. ${ }^{1} \mathrm{He}$ concluded that pulsation of the choroid plexus synchronous with the cardiac pulse is transmitted through the CSF, thereby suggesting that CSF pulsation originates in the choroid plexus. ${ }^{1}$ In 1962, Bering published cross-sectional brain images from a similar experiment performed in a kaolin-induced hydrocephalic dog. ${ }^{2}$ Ventricular dilatation was present on the side with an intact choroid plexus and an open foramen of Monro but was absent on the side on which a choroid plexectomy had been performed and the foramen of Monro was plugged. Taken together, these two sets of findings by Bering led to the conclusion that the arterial pulse synchronous with the cardiac pulse causes expansion and contraction of the intraventricular choroid plexus, and that this choroid plexus pulsation causes ventricular dilatation in the ventricular system in which the circulation was disrupted, ultimately leading to hydro- 
cephalus. However, Bering's experiments were conducted according to the techniques described in a previous article by Dandy. ${ }^{3}$ The methods of choroid plexectomy and plugging of the foramen of Monro in Dandy's article were extremely invasive, involving penetration to the cerebral ventricles through large-scale incisions into the cerebral hemispheres. Deformation of the cerebral hemisphere indicative of damage due to surgical manipulation is also apparent in the hydrocephalus brain sections presented by Bering.

The MRI techniques for observing CSF motion performed in our study are completely noninvasive with regard to the human brain. Moreover, pressure gradients can be quantitatively analyzed based on CSF velocity and continuously monitored within one cardiac pulse. If the choroid plexus were the source of CSF pulsation, it would repeatedly expand and contract in synchronization with the cardiac pulse, and it would undergo marked volume changes, generating a significant pressure gradient around the choroid plexus. In our study, no significant pressure gradient was observed around the choroid plexus, indicating that it does not perform this pumping action. This means that the choroid plexus is not the driving source for the origination of CSF pulsation. This finding is at odds with conventional wisdom regarding CSF circulation as described in textbooks and thus warrants attention. It may also be useful for elucidating hydrocephalus pathology. Because the MRI techniques used in our study can be easily replicated, we hope that others will conduct further research on this phenomenon.

In his Letter to the Editor, Dr. Picard states that he has not observed volumetric changes in the choroid plexus during the procedure of neuroendoscopy or on B-mode ultrasonography. Many neurosurgeons feel that the choroid plexus seems to be simply floating, not producing a significant volumetric change in the ventricular system; however, we have been unable to find any references in the published literature supporting this phenomenon. Findings that substantiate our MRI observations exist in the regular clinical setting of neuroendoscopic surgery. As Dr. Picard states, the classic theory contained in many textbooks postulating that well-known physiological phenomenon in which the choroid plexus is the driving force of CSF pulsation requires expeditious revision.

Mitsunori Matsumae, MD, DMSc Tokai University School of Medicine, Kanagawa, Japan

\section{References}

1. Bering EA Jr: Choroid plexus and arterial pulsation of cerebrospinal fluid; demonstration of the choroid plexuses as a cerebrospinal fluid pump. AMA Arch Neurol Psychiatry 73:165-172, 1955

2. Bering EA Jr: Circulation of the cerebrospinal fluid. Demonstration of the choroid plexuses as the generator of the force for flow of fluid and ventricular enlargement. J Neurosurg 19:405-413, 1962

3. Dandy WE: Experimental hydrocephalus. Ann Surg 70:129-142, 1919

\section{INCLUDE WHEN CITING}

Published online December 19, 2014; DOI: 10.3171/2014.6.JNS141331.

CAANS, 2015 